OPEN ACCESS

Edited by: Giovanna Suzzi, Università degli Studi di Teramo, Italy

Reviewed by: Charalampos Vasilios Proestos, National and Kapodistrian University

of Athens, Greece

Giulia Tabanelli,

Università degli Studi di Bologna, Italy

${ }^{*}$ Correspondence:

Fatih Özogu

fozogul@cu.edu.tr

Specialty section:

This article was submitted to

Food Microbiology,

a section of the journal

Frontiers in Microbiology

Received: 16 August 2018

Accepted: 10 October 2018

Published: 25 October 2018

Citation:

Özogul F, Šimat V, Gokdogan S, Regenstein JM and Özogul Y (2018) Effect of Natural Zeolite (Clinoptilolite) on in vitro Biogenic Amine Production by Gram Positive and Gram Negative Pathogens. Front. Microbiol. 9:2585.

doi: 10.3389/fmicb.2018.02585

\section{Effect of Natural Zeolite} (Clinoptilolite) on in vitro Biogenic Amine Production by Gram Positive and Gram Negative Pathogens

\author{
Fatih Özogul'*, Vida Šimat², Saadet Gokdogan', Joe M. Regenstein ${ }^{3}$ and Yesim Özogul ${ }^{1}$ \\ ${ }^{1}$ Department of Seafood Processing Technology, Faculty of Fisheries, Cukurova University, Adana, Turkey, ${ }^{2}$ Department \\ of Marine Studies, University of Split, Split, Croatia, ${ }^{3}$ Department of Food Science, Cornell University, Ithaca, NY, \\ United States
}

The effect of two levels of clinoptilolite (1 and 5\%) on the production of biogenic amines (BA) and ammonia (AMN) by Gram positive (Staphylococcus aureus, Enterococcus faecalis, and Listeria monocytogenes) and Gram negative bacteria (Aeromonas hydrophila, Klebsiella pneumoniae, Escherichia coli, Pseudomonas aeruginosa, and Salmonella Parathypi A), in tyrosine decarboxylase broth (TDB) was studied. A. hydrophila and E. coli produced the highest amounts of amines which were 1223.06 and $2627.90 \mathrm{mg} / \mathrm{l}$, respectively. All strains were able to decarboxylate tyrosine to tyramine (TYR) with E. coli being the highest (1657.19 mg/l). A. hydrophila formed $>50 \mathrm{mg} / \mathrm{l}$ histamine (HIS) while the other strains produced none or very low concentrations $(<4 \mathrm{mg} / \mathrm{l})$. Among Gram-positive pathogens, E. faecalis was characterized as the main amine producer (478.23 mg/l). Although dependent on bacterial strain and level used, the natural zeolite clinoptilolite can be used to decrease $\mathrm{BA}$ and $\mathrm{AMN}$ production by bacterial strains that are of health concern.

Practical Applications: Uses of natural prodcuts for biogenic amines inhibition. Clinoptilolite was used to reduce the amounts of amines such as spermine, putrescine, and dopamine produced by pathogenic and spoilage bacteria.

Keywords: clinoptilolite, tyramine, histamine, biogenic amines, food-borne pathogen

\section{INTRODUCTION}

Non-volatile organic nitrogenous compounds such as biogenic amines (BA) are found in a wide variety of foods, where they are formed by microbial decarboxylation of the precursor amino acids and their accumulation is related to bacterial spoilage thus they are considered undesirable compounds in food (Veciana-Nogués et al., 1997). The consumption of food containing high concentrations of BA has been associated with toxic effects and constitutes a potential health hazard and a food safety issue. The compounds mainly implicated in the direct toxic effect or interactions with some medical treatments are histamine (HIS) and tyramine (TYR).

The ability of bacteria to decarboxylate amino acids is highly variable as markedly different profiles of BA have been reported. This depends on various factors: the bacterial species, which are also strain-dependent, the availability of substrate amino acids, the presence of the intrinsic and extrinsic parameters of food that allow bacterial growth, the decarboxylase synthesis and decarboxylase activity (Özogul, 2011; Gokdogan et al., 2012). Species of some 
genera such as Staphylococcus, Enterococcus, Bacillus, Clostridium, Klebsiella, Escherihia, Proteus, Pseudomonas, Shigella, Photobacterium, Citrobacter and the lactic acid bacteria have the capability to decarboxylate one or more amino acids producing high levels of BA in foods and different media (Özogul and Özogul, 2007; Gokdogan et al., 2012).

Gardini et al. (2016) and Doeun et al. (2017) reviewed factors affecting biogenic amine content in foods including hygienic of raw materials, microbial composition, fermentation condition, the use of starter culture, technological additives, effects of packaging, other non-thermal treatments, metabolizing BA by microorganisms, effects of pressure treatments on BA formation, and antimicrobial substances. The effective inhibitory effect of some food additives and spices (glycine, garlic, clove, cinnamon, and clinoptilolite) on BA production and growth of BA-forming bacteria had been reported (Uchida et al., 1992; Mah and Hwang, 2009; Gokdogan et al., 2012; Zhou et al., 2016).

Clinoptilolite (zeolites) is used in various applications such as a chemical sieve, a gas absorber, a feed additive, or food additive, an odor control agent and as a water filter for municipal and residential drinking water and aquariums due to its large amount of pore space, high resistance to extreme temperatures, and chemically neutral basic structure (Polat et al., 2004). Zeolites are microporous and crystalline aluminosilicate minerals that retain and slowly release cations. Their low coats and non-toxic and heat stable properties make them attractive carriers for antimicrobial metal ions such as $\mathrm{Ag}+$. Cation exchange, especially silver exchange, is one of the properties of zeolites that give them prolonged antimicrobial properties (McDonnel and Pretzer, 2001; Top and Ülkü, 2004). This makes zeolites microbicide properties of great interest not only in food pathogen application, but over a wide range of applications against Gram-positive and Gram-negative bacteria (Narin et al., 2010; Johari et al., 2014). In histidine decarboxylase broth (HDB), the addition of clinoptilolite suppressed the BA production by Gram-negative FBP strains (Gokdogan et al., 2012) while in vitro studies showed its bactericidal effect against P. aeruginosa, S. aureus, and E. coli (Uchida et al., 1992). Additionally, the addition of a natural zeolite reduced BA in vacuum-packed sardines, especially HIS and TYR (Kuley et al., 2012). Since bacteria produce different amounts of BA in different decarboxylase broths, the aim of the study was to investigate $\mathrm{BA}$ and ammonia (AMN) formation by Grampositive and Gram-negative food borne pathogens (FBP) in tyrosine decarboxylase broth (TDB) at two different levels (1 and $5 \%)$ of clinoptilolite.

\section{MATERIALS AND METHODS}

\section{Clinoptilolite}

Clinoptilolite was provided by Enli Madencilik Sanayi ve Ticaret A.Ş., Izmir, Turkey.

\section{Foodborne Pathogens}

The eight pathogens used were obtained from the American Type Culture Collection (Rockville, MD, United States). The bacteria were as follow: Listeria monocytogenes (ATCC7677), Staphylococcus aureus (ATCC29213), Klebsiella pneumoniae (ATCC700603), Escherichia coli (ATCC25922), Enterococcus faecalis (ATCC29212), and Pseudomonas aeruginosa (ATCC27853). Aeromonas hydrophila (NCIMB1135) was obtained from the National Collections of Industrial Food and Marine Bacteria (Aberdeen, United Kingdom) and Salmonella Parathypi A (NCTC13) was supplied by the National Collection of Type Cultures (London, United Kingdom).

\section{Culture Media and Extraction of the Bacterial Supernatant}

The formation of TYR by all FBP strains was monitored using TDB according to Klausen and Huss (1987): One g peptone (Oxoid, Hamshire, England), 0.5 g Lab-Lemco powder (Oxoid, Hamshire, England), 2.5 g Sodium chloride, $4.01 \mathrm{~g}$ L-tyrosine $\mathrm{HCl}$ (Merck, Darmstadt, Germany), and $2.5 \mathrm{mg}$ pyridoxal $\mathrm{HCl}$ (Merck, Darmstadt, Germany) were added into $500 \mathrm{ml}$ distilled water. The initial $\mathrm{pH}$ of the broth was 6.6-6.8 and $\mathrm{pH}$ was adjusted depending on the optimum $\mathrm{pH}$ growth of pathogens with $1 \mathrm{M}$ Sodium hydroxide or $0.1 \mathrm{M} \mathrm{HCl}$ using a WTW $315 \mathrm{i} \mathrm{pH}$ Meter (Weilheim, Germany). Prior to use, the TDB was pipetted $(10 \mathrm{ml}$ bottles) and autoclaved for $15 \mathrm{~min}$ at $121^{\circ} \mathrm{C}$

Nutrient broth (Merck, Darmstadt, Germany) was used for the pathogen cultures. The bacterial strains were incubated for 2 or 3 days in their optimum growth temperature after which $0.5 \mathrm{ml}$ of these pathogenic cultures were transferred to the TDB to perform the tyrosine decarboxylation. Two levels (1 and 5\%) of clinoptilolite (Enli Madencilik Sanayi ve Ticaret A.Ş., Izmir, Turkey) were added.

For the extraction of supernatant from the FBP strains, $5 \mathrm{ml}$ of the TDB that contains the pathogens were put in bottles with $2 \mathrm{ml}$ trichloroacetic acid. Centrifugation was performed using a Hettich 32R centrifuge (Tuttlingen, Germany) at $3000 \times g$ for $10 \mathrm{~min}$ and then filtered through Whatman No. 1 filter paper (Maidenstone, United Kingdom). For the derivatization $4 \mathrm{ml}$ of supernatant were taken from each sample.

\section{Chemical Reagents}

L-tyrosine monohydrochloride (H8125) and all amine standards were bought from Sigma-Aldrich (Sigma-Aldrich, Munich, Germany). For amine and ammonia analyses acetonitrile and HPLC grade water were used.

\section{Preparation of Standard Amine Solution}

For the preparation of the solution, amines were dissolved in $10 \mathrm{ml} \mathrm{HPLC}$ grade water, to reach a final concentration of $10 \mathrm{mg} / \mathrm{ml}$ solution for each free biogenic amine. The concentration was as followed: ammonium chloride (296.9 mg), putrescine dihydrochloride (182.9 mg), agmatine sulfate (175.4 mg), spermidine trihydrochloride $(175.3 \mathrm{mg})$, spermine tetrahydrochloride $(172.0 \mathrm{mg})$, cadaverine dihydrochloride (171.4 mg), HIS dihydrochloride (165.7 mg), trimethylamine hydrochloride (161.7 mg), 5-hydroxytryptamine (serotonin) (133.9 mg), 2-phenylethylamine hydrochloride (130.1 mg), 
Tyramine hydrochloride (126.7 mg), 3-hydroxytyramine hydrochloride (dopamine) (123.8 $\mathrm{mg})$, and typtamine hydrochloride (122.8 mg).

\section{Derivatization}

A stock solution was prepared by dissolving $2 \%$ benzoyl chloride (Sigma-Aldrich, Munich, Germany) in acetonitrile to improve the reaction with amines. For derivatization of standard amine solutions, $100 \mu \mathrm{l}$ were taken ( $4 \mathrm{ml}$ for extracted bacterial cultures) from each free BA standard solution $(10 \mathrm{mg} / \mathrm{ml})$. Sodium hydroxide $(1 \mathrm{ml}$ of $2 \mathrm{M}$ ) and $1 \mathrm{ml}$ of $2 \%$ benzoyl chloride (dissolved in acetonitrile) were used and the solution was blended on a Vortex a ZX3 mixer (Welp Scientifica, Milano, Italy) for $1 \mathrm{~min}$. The reaction mixture was left at room temperature $\left(23^{\circ} \mathrm{C}\right)$ for $5 \mathrm{~min}$ and then centrifuged using a Hettich 32R centrifuge (Tuttlingen, Germany) at $3000 \times g$ for $10 \mathrm{~min}$. Addition of $2 \mathrm{ml}$ of saturated sodium chloride solution was used to stop the benzoylation and the solution was extracted with $2 \mathrm{ml}$ of diethyl ether twice. The organic layer on top was relocated into a clean tube after blending. The organic layer was then removed by a stream of nitrogen until dryness. Prior to injection (10 $\mu \mathrm{l}$ aliquots) into HPLC, the residue was dissolved in $1 \mathrm{ml}$ of acetonitrile.

\section{Analytical Method}

Biogenic amines, ammonia, and trimethylamine were analyzed with Özogul (2004) method and measured as mg compound per liter broth. The rapid HPLC technique with a reversed phase column and a gradient elution program were used.

The HPLC instrument (Shimadzu, Kyoto, Japan) is equipped with a column oven (CTO-20AC), auto sampler (SIL 20AC), two binary gradient pumps (Shimadzu LC-10AT), SPD-M20A diode array detector, and a communication bus module (CBM-20A) with a valve unit FCV-11AL. A reverse-phase column, Spherisorb 5 Si C18 pH-St, $250 \mathrm{~mm} \times 4.6 \mathrm{~mm}$ (Phenomenex, Macclesfield, Cheshire, United Kingdom) was used. Ammonia and TMA are measured using the same method with the other BA at the same injection.

BAs analysis were done using continuous gradient elution with acetonitrile (eluent A) and HPLC grade water (eluent B). The total separation time was $20 \mathrm{~min}$ and the injection volume was $10 \mu \mathrm{L}$. Detection wavelength was at $254 \mathrm{~nm}$. A standard curve for ammonia and all amines in the range of $0-50 \mathrm{mg} / \mathrm{mL}$ was prepared. Correlation coefficient of peak area against amine standard concentrations for each compound was calculated after injecting five replicates of each standard solution of amine. The correlation coefficient ( $r 2$ ) in the curve was $>0.99$ for each benzoylated amine and ammonia.

\section{Data Analysis}

The mean value and SD were calculated from four samples for each treatment. To determine the significance of differences one way ANOVA was used $(P<0.05)$. SPSS 15.0 for Windows (SPSS Inc., Chicago, IL, United States) was used to carry the statistics.

\section{RESULTS AND DISCUSSION}

\section{Biogenic Amine and Ammonia Production}

The accumulation of AMN, BA, and trimethylamine (TMA) by Gram-negative and Gram-positive bacteria is shown in Table 1. All Gram-negative strains formed significant $(P<0.05)$ amounts of AMN (155 to $338 \mathrm{mg} / \mathrm{l}$ ). The Gram-negative strains A. hydrophila and E. coli produced the highest total amounts of amines in TDB (1220 and $2630 \mathrm{mg} / \mathrm{l}$, respectively). These two strains also produced the highest concentrations of AMN, PUT, CAD, phenylethylamine (PHEN), SPM, and AGM, making them the most potential toxic strains. A. hydrophila formed $>50 \mathrm{mg} / \mathrm{l}$ HIS while other tested strains produced none or very low concentrations $(<4 \mathrm{mg} / \mathrm{l})$. E coli produced significantly $(P<0.05)$ more TYR than the other Gram-negative bacteria. Among the Gram-negative bacteria, K. pneumonia and S. paratyphi A were characterized as the lowest HIS and TYR producers. SPD, SER, PHEN, and DOP were generally produced in low to medium levels, with the exception of DOP production by $S$. paratyphi $\mathrm{A}$ and $A$. hydrophila that was somewhat higher. Tested FBP strains produced significant $(P<0.05)$ amount of SPM and AGM as well. Sixteen isolates of genus Pseudomonas were unable to generate BA according to some reports (Bunkková et al., 2010). On the other hand, Pseudomonas spp. from Portuguese vacuum-packed cold-smoked fish was determined as good HIS producers (da Silva et al., 2002). Özogul and Özogul (2007) reported that different strains of K. pneumoniae accumulated different amounts of HIS, thus $K$. pneumoniae strain 673 formed $>3400 \mathrm{mg} / \mathrm{l}$ HIS from histidine, whilst E. faecalis, K. pneumoniae (8152), and K. pneumoniae (2122) produced $<10 \mathrm{mg} / \mathrm{l} \mathrm{HIS}$. In regard to the production of PUT and CAD, tested strains formed low to medium levels in TDB (Table 1). Enterobacteriaceae and Pseudomonas spp. are considered the main producers of PUT in various types of food, from fermented to chilled fish, meat, and cheese products (Wunderlichová, 2014).

The formation of AMN and BA by foodborne pathogens in HDB, TDB, and lysine decarboxylase broth (LDB) was previously reported (Kuley and Özogul, 2011; Gokdogan et al., 2012; Özogul et al., 2016). In HDB and LDB five Gram-negative (E. coli, K. pneumoniae, A. hydrophila, S. Paratyphi A, and P. aeruginosa) and three Gram-positive FBP (S. aureus, E. faecalis, and $L$. monocytogenes) were able to decarboxylate more than one amino acid and produce not only HIS and CAD but also other amines.

In this work, Gram-positive pathogens formed lower concentrations of BA than Gram-negative bacteria and among them $E$. faecalis was demonstrated as the main amine producer $(478.23 \mathrm{mg} / \mathrm{l}$ ) (Table 1). It is interesting to point out the differences of our results to other obtained for AMN and BA production by Gram-positive bacteria in HDB and LDB. In HDB, Gokdogan et al. (2012) found E. faecalis to be the main producer of AMN $(125.49 \mathrm{mg} / \mathrm{l})$ and all investigated BA (production levels were $<20 \mathrm{mg} / \mathrm{l})$. In LDB, $S$. aureus produced the highest amounts of AMN (222.99 mg/l) and most BA (PUT; CAD, 


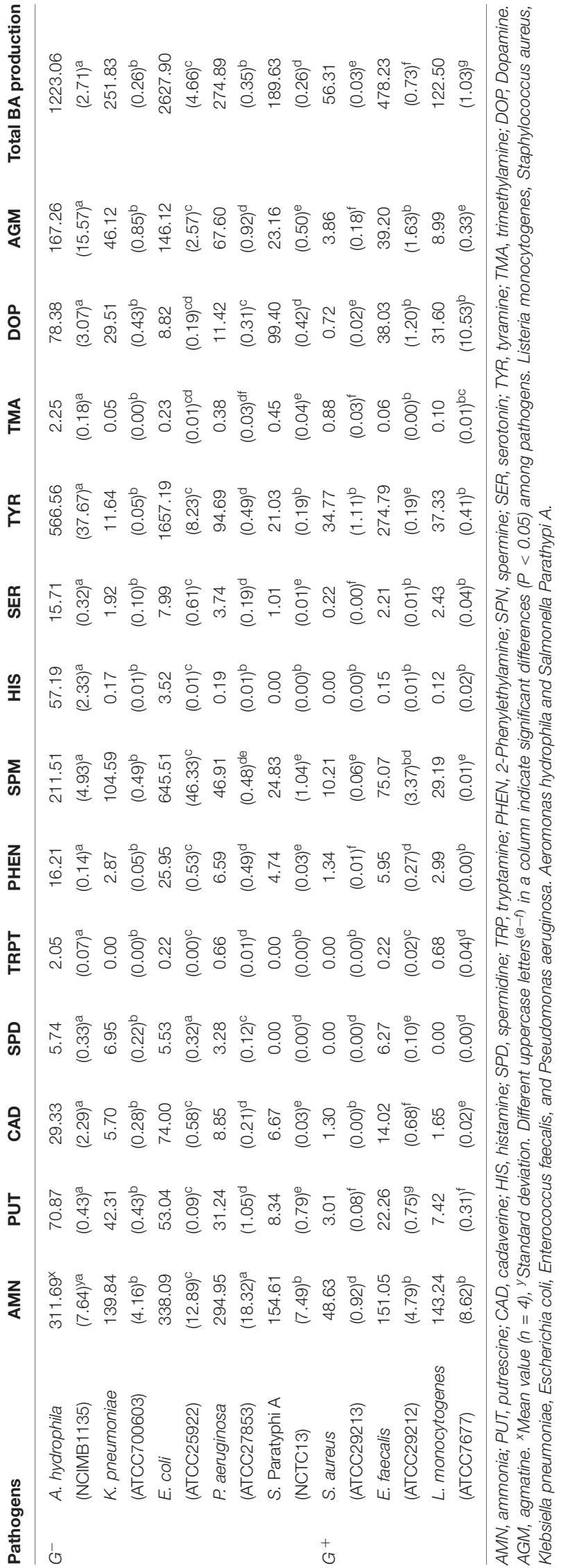

PHEN, HIS, and DOP) while E. faecalis produced high levels of SER, TYR, and AGM (Özogul et al., 2016). Interestingly, in HDB E. faecalis and S. aureus produced very low levels of HIS $(<0.50 \mathrm{mg} / \mathrm{l}), \mathrm{CAD}(<4 \mathrm{mg} / \mathrm{l})$, and TYR $(<5 \mathrm{mg} / \mathrm{l})$ (Gokdogan et al., 2012) while in LDB the production levels were higher for all three BA, thus E. faecalis produced $65.24 \mathrm{mg} / \mathrm{l}$ of TYR while $S$. aureus produced $124.75 \mathrm{mg} / \mathrm{l}$ of CAD and $40.44 \mathrm{mg} / \mathrm{l}$ of HIS (Özogul et al., 2016). L. monocytogenes was characterized as the lowest AMN and BA Gram-positive producer in HDB (Gokdogan et al., 2012), TDB (this study) and LDB (Özogul et al., 2016). Beside AMN production (52.29 $\mathrm{mg} / \mathrm{l}$ in HDB, $111.31 \mathrm{mg} / \mathrm{l}$ in LDB, and $143.24 \mathrm{mg} / \mathrm{l}$ in TDB), moderate levels of DOP $(44.55 \mathrm{mg} / \mathrm{l})$ formation in LDB (Özogul et al., 2016) and around $30 \mathrm{mg} / \mathrm{l}$ of TYR, SPM, and DOP production in TDB L. monocytogenes showed no ability to produce significant levels of BA.

Recently, there have been studies confirming enterococci species as tyramine- and putrescine-producer bacteria (Ladero et al., 2012; Marcobal et al., 2012). It was reported by Özogul and Özogul, 2007 that TYR was formed in highest concentration $(526 \mathrm{mg} / \mathrm{L})$ by E. faecalis. Various E. faecalis strains are able to yield TYR from 601 to $4986 \mu \mathrm{g} / \mathrm{mL}$ (Bover-Cid and Holzapfel, 1999; Connil et al., 2002). The strains of E. faecalis are very frequently found to be putrescine-producers (Llácer et al., 2007; Ladero et al., 2012), additionally our result confirm its ability to form significant concentrations of all tested BA in TDB. However, in HDB E. faecalis produced significantly lower concentrations of BA than in TDB, among them TYR, and PUT were $4.06 \mathrm{mg} / \mathrm{l}$ and $12.43 \mathrm{mg} / \mathrm{l}$ (Gokdogan et al., 2012). Kuley and Özogul (2011) reported accumulation of total amine formation as $330 \mathrm{mg} / \mathrm{l}$ for A. hydrophila and $884 \mathrm{mg} / \mathrm{l}$ for E. faecalis in TDB, and also $S$. Paratyphi A was characterized as the main amine former $(4601 \mathrm{mg} / \mathrm{l})$. In this study, A. hydrophila was observed as main AMN and BA producer in TDB, and E. faecalis as main Gram-positive producer, while total amine production by $S$. Paratyphi A was moderate, but lower than other bacterial strains ( $189.63 \mathrm{mg} / \mathrm{l})$. In this study, S. Paratyphi A and S. aureus showed no ability to produce SPD, TRPT, or HIS. TMA was produced at low levels $(0.05-2.25 \mathrm{mg} / \mathrm{l})$ with $A$. hydrophila being the highest producer.

Gram-negative and positive FBPs showed the ability to produce significant amounts of TYR and other BA, as well as AMN and TMA in TDB. The most significant and prolific producer of TYR was Gram-negative strain E. coli (>1000 mg/l), followed by $A$. hydrophila $(>500 \mathrm{mg} / \mathrm{l})$ and Gram-positive E. faecalis (>205 mg/l). In TDB, these three strains produced the highest concentrations of other BA and AMN.

\section{The Influence of Natural Zeolite on AMN and BA Production by Gram-Positive and Gram-Negative FBP in TDB}

The effect of zeolite on the studied compounds by Gram-negative FBP in TDB are shown in Figure 1. The 1\% zeolite significantly reduced ANM production by all Gram-negative FBP, which were further reduced at $5 \%$ with the exception of $P$. aeruginosa. Generally, the effect of zeolite was dependent on bacterial strains 


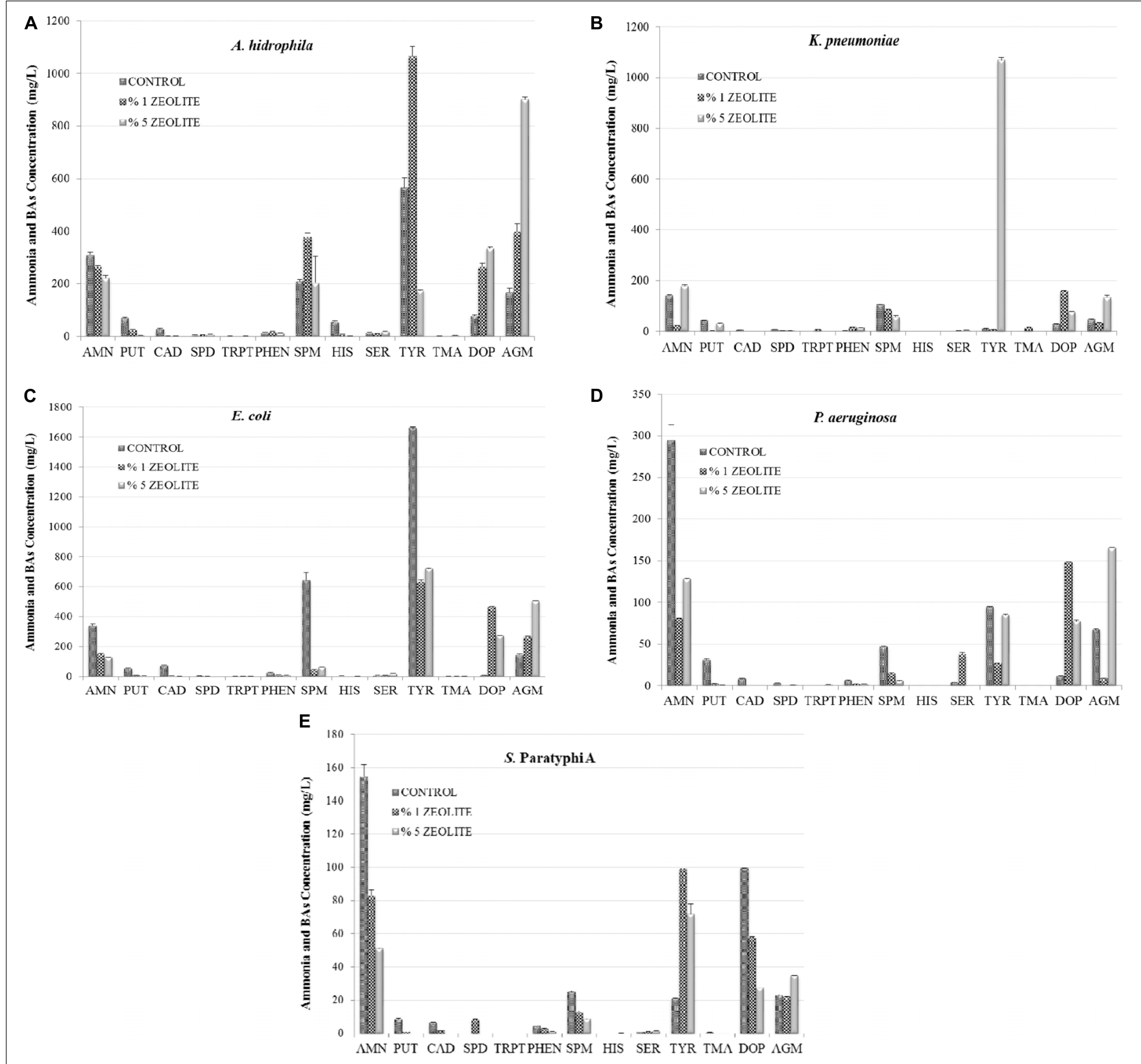

FIGURE 1 | The effect of zeolite addition on amine formation (AMN, ammonia; PUT, putrescine; CAD, cadaverine; HIS, histamine; SPD, spermidine; TRP, tryptamine; PHEN, 2-Phenylethylamine; SPN, spermine; SER, serotonin; TYR, tyramine; TMA, trimethylamine; DOP, Dopamine; AGM, agmatine) by Gram-negative foodborne pathogens A. hydrophila (A), K. pneumoniae (B), E. coli (C), P. aeruginosa (D), S. Paratyphi A (E) in tyrosine decarboxylase broth.

and zeolite level since there was either stimulation or inhibition effect on the BAs production. For instance, $1 \%$ zeolite reduced TYR production by E. coli and P. aeruginosa, but $5 \%$ zeolite increased it. DOP and AGM production was stimulated at both 1 and $5 \%$ zeolite.

Figure 2 shows the influence of zeolite on AMN and BA production by Gram-positive FBP. The 1\% zeolite lowered AMN production by $L$. monocytogenes and E. faecalis significantly $(P<0.05)$. The elimination of AMN by natural zeolites has been well investigated, especially in wastewater treatment where natural zeolite was found very efficient (for $50 \mathrm{mg} / \mathrm{l} \mathrm{AMN}$ 99.74\% removal) (Wang and Peng, 2010; Zabochnicka-Świątek and Maliñska, 2010; Widiastuti et al., 2011). Additionally, the effect of natural clinoptilolite on $\mathrm{AMN}$ and other BA formation by FBP was studied in HDB and LDB (Gokdogan et al., 2012; Özogul et al., 2016). As in this work, in both studies the influence of zeolite was linked to the bacterial strains and to the zeolite concentrations. AMN production was higher in $\mathrm{HDB}$ with $1 \%$ zeolite while the zeolite addition showed a suppressive effect on HIS and especially TYR formations 

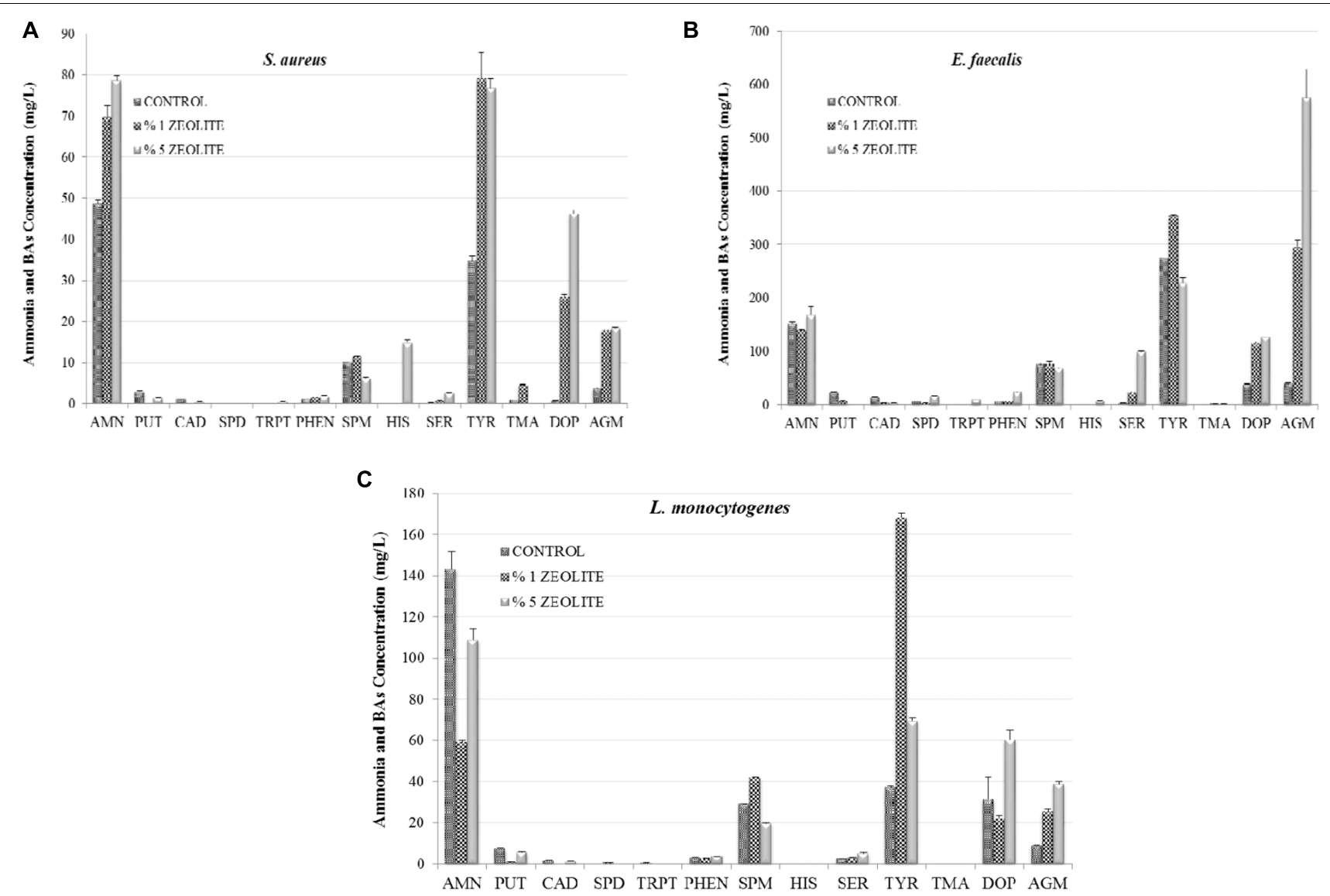

FIGURE 2 | The influence of addition of zeolite on amine formation (AMN, ammonia; PUT, putrescine; CAD, cadaverine; HIS, histamine; SPD, spermidine; TRP, tryptamine; PHEN, 2-Phenylethylamine; SPN, spermine; SER, serotonin; TYR, tyramine; TMA, trimethylamine; DOP, Dopamine; AGM, agmatine) by Gram-positive foodborne pathogens S. aureus (A), E. faecalis (B), L. momocytogenes (C) in tyrosine decarboxylase broth.

by Gram-negative FBP that were more sensitive compared to Gram-positive bacteria. Gokdogan et al. (2012) found that zeolite eliminated HIS accumulation by $S$. paratyphi A, E. coli, and $P$. aeruginosa $(P<0.05)$, but stimulated HIS formation by $A$. hydrophila and $K$. pneumonia. The addition of zeolite at $1 \%$ level increased TYR generation by Aeromonas spp. and Escherichia spp. and it was also determined that the 5\% zeolite stimulated TYR production by Pseudomonas spp. and $K$. pneumonia. Özogul et al. (2016) also found that E. coli was able to decrease the AMN content as $132.35 \mathrm{mg} / \mathrm{l}$ ( $1 \%$ zeolite) and $121.21 \mathrm{mg} / \mathrm{l}$ ( $5 \%$ zeolite) were determined in LDB. This effect was observed for S. Paratyphi A but only at 5\% level. Regarding the other bacteria important inhibitions of $5 \%$ zeolite was detected on AMN formation by K. pneumoniae (from 126.15 to $91.92 \mathrm{mg} / \mathrm{l}$ ), P. aeruginosa (from 120.32 to $88 \mathrm{mg} / \mathrm{l}$ ), and A. hydrophila (from 239.93 to $126.78 \mathrm{mg} / \mathrm{l})$. On the other hand the adding zeolite at $1 \%$ elevated the AMN generation by S. Paratyphi from 83.01 to $87.05 \mathrm{mg} / \mathrm{l}$ (Özogul et al., 2016).

In this work the inhibitor effect of $1 \%$ zeolite was observed in PUT and CAD accumulation by all three tested Gram-positive FBP. Although HIS production by S. aureus and E. faecalis was very low or none in control group, there was a little stimulation effect of $5 \%$ zeolite addition in TDB. L. monocytogenes showed no ability to produce significant HIS in these conditions $(0.12 \mathrm{mg} / \mathrm{l})$, but the formation of SPM, TYR, and AGM was stimulated in presence of $1 \%$ zeolite $(41.98,168.23$, and $25.77 \mathrm{mg} / \mathrm{l}$, respectively). Addition of zeolite also simulated TYR, SER, DOP and AGM accumulations by Gram-positive FBP in TDB. The influence of zeolite on BA production by FBP in HDB has also shown dependence on pathogenic strains and zeolite concentrations (Gokdogan et al., 2012). Zeolite also showed to be suitable in food application; in a dynamic system such as fish. Its application had a direct effect on microbial growth in vacuum packed sardine filets and resulted in significant reduction of AMN and BA production during storage and at the same time its application improved sensory quality of the sardine in terms of off-odor removal (Kuley et al., 2012).

\section{CONCLUSION}

This study showed that A. hydrophila and E. coli produced the highest amounts of amines which were 1220 and $2630 \mathrm{mg} / \mathrm{l}$, 
respectively. All strains were able to decarboxylate tyrosine to TYR, especially E. coli (>1600 mg/l). Among the bacteria, A. hydrophila produced $>50 \mathrm{mg} / \mathrm{l}$ HIS whereas the other strains formed none or very low levels of HIS ( $<4 \mathrm{mg} / \mathrm{l})$. Gram-negative bacterial strains produced higher concentrations of $\mathrm{AMN}$ and $\mathrm{BA}$ in TDB, and zeolite addition had more apparent effect, especially for reducing AMN, PUT, CAD, HIS, and TYR production. In Gram-positive bacterial strains, the zeolite showed more stimulating effect on TYR production, but reduced CAD and PUT formation in three tested bacterial strains. In conclusion, zeolite can be used as a natural additive to prevent the production of some BAs such as CAD and PUT produced by Gram-negative FBPs.

\section{REFERENCES}

Bover-Cid, S., and Holzapfel, W. H. (1999). Improved screening procedure for biogenic amine production by lactic acid bacteria. Int. J. Food Microbiol. 53, 33-41. doi: 10.1016/S0168-1605(99)00 $152-\mathrm{X}$

Buňková, L., Buňka, F., Klčovská, P., Mrkvička, V., Doležalová, M., and Kráčmar, S. (2010). Formation of biogenic amines by Gram-negative bacteria isolated from poultry skin. Food Chem. 121, 203-206. doi: 10.1016/j.foodchem.2009. 12.012

Connil, N., Breton, Y. L., Dousset, X., Auffray, Y., Rincé, A., and Préevost, H. (2002). Identification of the Enterococcus faecalis tyrosine decarboxylase operon $\imath$ nvolved in tyramine production. Appl. Environ. Microbiol. 68, 3537-3544. doi: 10.1128/AEM.68.7.3537-3544.2002

da Silva, M. V., Pinho, O., Ferreira, I., Plestilová, L., and Gibbs, P. A. (2002). Production of histamine and tyramine by bacteria isolated from portuguese vacuum-packed cold-smoked fish. Food Control 13, 457-461. doi: 10.1016/ S0956-7135(01)00081-0

Doeun, D., Davaatseren, M., and Chung, M. S. (2017). Biogenic amines in foods. Food Sci. Biotech. 26, 1463-1474. doi: 10.1007/s10068-0170239-3

Gardini, F., Ozogul, Y., Suzzi, G., Tabanelli, G., and Ozogul, F. (2016). Technological factors affecting biogenic amine content in foods: a review. Front. Microbiol. 7:1218. doi: 10.3389/fmicb.2016.01218

Gokdogan, S., Özogul, Y., Kuley, E., Özogul, F., Kacar, C., and Ucar, Y. (2012). The influences of natural zeolite (cliptinolite) on ammonia and biogenic amine formation by foodborne pathogen. J. Food Sci. 77, M452-M457. doi: 10.1111/j. 1750-3841.2012.02822.x

Johari, S. A., Kalbasi, M. R., and Yu, I. J. (2014). Inhibitory effects of silver zeolite on in vitro growth of fish egg pathogen, saprolegnia sp. J. Medic. 2, 357-361.

Klausen, N. K., and Huss, H. H. (1987). Growth and histamine production by Morganella morganii under various temperature conditions. Int. J. Food Microbiol. 5, 147-156. doi: 10.1016/0168-1605(87)900 $32-8$

Kuley, E., and Özogul, F. (2011). Synergistic and antagonistic effect of lactic acid bacteria on tyramine production by food-borne pathogenic bacteria in tyrosine decarboxylase broth. Food Chem. 127, 1163-1168. doi: 10.1016/j.foodchem. 2011.01.118

Kuley, E., Özogul, F., Durmus, M., Gokdogan, S., Kacar, C., Özogul, Y., et al. (2012). The impact of applying natural clinoptilolite (zeolite) on the chemical, sensory and microbiological changes of vacuum packed sardine fillets. Int. J. Food Sci. Tech. 47, 1977-1985. doi: 10.1111/j.1365-2621.2012.03060.x

Ladero, V., Fernández, M., Calles-Enríquez, M., Sánchez-Llana, E., Cañedo, E., Martín, M. C., et al. (2012). Is biogenic amines production a strain-dependent trait in enterococci? Food Microbiol. 30, 132-138. doi: 10.1016/j.fm.2011. 12.016

Llácer, J. L., Polo, L. M., Tavárez, S., Alarcón, B., Hilario, R., and Rubio, V. (2007). The gene cluster for agmatine catabolism of Enterococcus faecalis. Studies of recombinant putrescine transcarbamylase and agmatine deiminase

\section{AUTHOR CONTRIBUTIONS}

FÖ and VŠ wrote the final version of the article. YÖ and SG performed all experiments, such as preparation of culture media and extraction of supernatant from pathogens, derivatization of biogenic amines. FÖ performed HPLC analyses of biogenic amines. JR edited the article.

\section{FUNDING}

Cukurova University provided funding for the project (Project Number: SUF2010YL6).

and a snapshot of agmatine deiminase catalyzing its reaction. J. Bacteriol. 189, 1254-1265. doi: 10.1128/JB.01216-06

Mah, J. H., and Hwang, H. J. (2009). Effects of food additives on biogenic amine formation in myeolchi-jeot, a salted and fermented anchovy (Engraulis japonicus). Food Chem. 114, 168-173. doi: 10.1016/j.foodchem.2008. 09.035

Marcobal, A., De Las Rivas, B., Landete, J. M., Tabera, L., and Muñoz, R. (2012). Tyramine and phenylethylamine biosynthesis by food bacteria. Crit. Rev. Food Sci. Nutr. 52, 448-467. doi: 10.1080/10408398.2010.50 0545

McDonnel, G., and Pretzer, D. (2001). "New and developing chemical antimicrobials," in Disinfection, Sterilization and Preservation, ed. S. S. Block (Philadelphia, PA: Lippincott Williams \& Wilkins), 431-444.

Narin, G., Bulut, A. Ç, and Ülkü, S. (2010). Antibacterial and bactericidal activity of nitric oxide-releasing natural zeolite. Appl. Clay Sci. 50, 560-568. doi: 10.1016/ j.clay.2010.10.013

Özogul, F. (2004). Production of biogenic amines by Morganella morganii, Klebsíella pneumoniae and hafnia alvei using a rapid HPLC method. Eur. Food Res. Technol. 219, 465-469. doi: 10.1007/s00217-0040988-0

Özogul, F. (2011). Effects of specific lactic acid bacteria species on biogenic amine production by foodborne pathogen. Int. J. Food Sci. Technol. 46, 478-484. doi: 10.1111/j.1365-2621.2010.02511.x

Özogul, F., Hamed, I., and Gokdogan, S. (2016). The impact of natural clinoptilolite on ammonia, cadaverine and other polyamine formation by food-borne pathogen in lysine decarboxylase broth. LWT Food Sci. Technol. 65, 703-710. doi: 10.1016/j.lwt.2015.08.072

Özogul, F., and Özogul, Y. (2007). The ability of biogenic amines and ammonia production by single bacterial cultures. Eur. Food Res. Technol. 225, 385-394. doi: 10.1007/s00217-006-0429-3

Polat, E., Karaca, M., Demir, H., and Onus, N. (2004). Use of natural zeolite (clinoptilolite) in agriculture. J. Fruit Ornam. Plant Res. 12, 183-189.

Top, A., and Ülkü, S. (2004). Silver, zinc, and copper exchange in a Na-clinoptilolite and resulting effect on antibacterial activity. Appl. Clay Sci. 27, 13-19. doi: 10.1016/j.clay.2003.12.002

Uchida, T., Maru, N., Furuhata, M., Fujino, A., Muramoto, S., IshiBAhi, A., et al. (1992). Antibacterial zeolite ballon catheter and its potential for urinary tract infection control. Hinyokike Kiyo 38, 973-989.

Veciana-Nogués, M. T., Mariné-Font, A., and Vidal-Carou, M. C. (1997). Biogenic amines as hygienic quality indicators of tuna. Relationships with microbial counts, ATP-related compounds, volatile amines, and organoleptic changes. J. Agric. Food Chem. 45, 2036-2041. doi: 10.1021/jf96 09111

Wang, S., and Peng, Y. (2010). Natural zeolites as effective adsorbents in water and wastewater treatment. Chem. Eng. J. 156, 11-24. doi: 10.1016/j.cej.2009. 10.029

Widiastuti, N., Wu, H., Ang, H. M., and Zhang, D. (2011). Removal of ammonium from greywater using natural 
zeolite. Desalination 277, 15-23. doi: 10.1016/j.desal.2011. 03.030

Wunderlichová, L., Buňková, L., Koutný, M., Jančová, P., and Buňka, F. (2014). Formation, degradation, and detoxification of putrescine by foodborne bacteria: a review. Compr. Rev. Food Sci. Food 13, 2012-2030. doi: 10.1111/1541-4337. 12099

Zabochnicka-Świątek, M., and Maliñska, K. (2010). Removal of ammonia by clinoptilolite. Global NEST J. 12, 256-261.

Zhou, X., Qiu, M., Zhao, D., Lu, F., and Ding, Y. (2016). Inhibitory effects of spices on biogenic amine accumulation during fish sauce fermentation. J. Food Sci. 81, M913-M920. doi: 10.1111/1750-3841.13255
Conflict of Interest Statement: The authors declare that the research was conducted in the absence of any commercial or financial relationships that could be construed as a potential conflict of interest.

Copyright (C) 2018 Özogul, Šimat, Gokdogan, Regenstein and Özogul. This is an open-access article distributed under the terms of the Creative Commons Attribution License (CC BY). The use, distribution or reproduction in other forums is permitted, provided the original author(s) and the copyright owner(s) are credited and that the original publication in this journal is cited, in accordance with accepted academic practice. No use, distribution or reproduction is permitted which does not comply with these terms. 